University of Montana

ScholarWorks at University of Montana

10-2007

\title{
Native Plant Diversity Resists Invasion at both Low and High Resource Levels
}

John L. Maron

University of Montana - Missoula, john.maron@mso.umt.edu

Marilyn Marler

Follow this and additional works at: https://scholarworks.umt.edu/biosci_pubs

Part of the Biology Commons

Let us know how access to this document benefits you.

\section{Recommended Citation}

Maron, John L. and Marler, Marilyn, "Native Plant Diversity Resists Invasion at both Low and High Resource Levels" (2007). Biological Sciences Faculty Publications. 238.

https://scholarworks.umt.edu/biosci_pubs/238

This Article is brought to you for free and open access by the Biological Sciences at ScholarWorks at University of Montana. It has been accepted for inclusion in Biological Sciences Faculty Publications by an authorized administrator of ScholarWorks at University of Montana. For more information, please contact scholarworks@mso.umt.edu. 


\title{
NATIVE PLANT DIVERSITY RESISTS INVASION AT BOTH LOW AND HIGH RESOURCE LEVELS
}

\author{
John Maron ${ }^{1}$ And Marilyn Marler \\ Division of Biological Sciences, University of Montana, Missoula, Montana 59812 USA
}

\begin{abstract}
Human modification of the environment is causing both loss of species and changes in resource availability. While studies have examined how species loss at the local level can influence invasion resistance, interactions between species loss and other components of environmental change remain poorly studied. In particular, the manner in which native diversity interacts with resource availability to influence invasion resistance is not well understood. We created experimental plant assemblages that varied in native species (1-16 species) and/or functional richness (defined by rooting morphology and phenology; one to five functional groups). We crossed these diversity treatments with resource (water) addition to determine their interactive effects on invasion resistance to spotted knapweed (Centaurea maculosa), a potent exotic invader in the intermountain West of the United States. We also determined how native diversity and resource addition influenced plant-available soil nitrogen, soil moisture, and light. Assemblages with lower species and functional diversity were more heavily invaded than assemblages with greater species and functional diversity. In uninvaded assemblages, experimental addition of water increased soil moisture and plant-available nitrogen and decreased light availability. The availability of these resources generally declined with increasing native plant diversity. Although water addition increased susceptibility to invasion, it did not fundamentally change the negative relationship between diversity and invasibility. Thus, native diversity provided strong invasion resistance even under high resource availability. These results suggest that the effects of local diversity can remain robust despite enhanced resource levels that are predicted under scenarios of global change.
\end{abstract}

Key words: biological invasion; Centaurea maculosa; diversity-invasibility; exotic species; grassland; resource additions; soil nitrogen; spotted knapweed.

\section{INTRODUCTION}

Understanding factors that influence susceptibility of plant communities to invasion is a central concern, from a conceptual as well as a practical perspective (D'Antonio and Vitousek 1992, Fargione et al. 2003). Elton (1958) proposed long ago that an important attribute of species-rich communities is that they provide enhanced invasion resistance compared to more depauperate communities, and both theoretical (MacArthur 1970, Post and Pimm 1983, Case 1990, Tilman 2004) and empirical results support this idea (Levine 2000, Naeem et al. 2000, Dukes 2002, Kennedy et al. 2002, Fargione et al. 2003, Zavaleta and Hulvey 2004).

The negative relationship between plant community diversity and invasibility, however, has been found primarily in experiments in which other components of environmental variation have been controlled (but see Renne et al. 2006). Yet it is increasingly clear that the very environmental factors that diversity-invasibility experiments have traditionally ignored can themselves have large effects on community invasibility. For

Manuscript received 29 November 2006; revised 5 February 2007; accepted 23 February 2007. Corresponding Editor: T. J. Stohlgren.

${ }^{1}$ E-mail: john.maron@mso.umt.edu example, increased resource availability can strongly facilitate invasion (Aerts and Berendse 1988, Hobbs and Huenneke 1992, Milchunas and Lauenroth 1995, Wedin and Tilman 1996, Davis and Pelsor 2001, Thomsen et al. 2006). The potentially opposing forces of native plant diversity and extrinsic factors such as resource availability or propagule pressure (Von Holle and Simberloff 2005) have led to the current situation in which "The question now is not whether diversity is important, but how important is it relative to predation, disturbance, productivity, propagule supply, and other actors known to affect invasion success?" (Stachowicz et al. 2002). Some have suggested that resource availability is of such general importance that after accounting for it there will be no meaningful relationship between native diversity and invasibility (Davis et al. 2000). More recently, Renne et al. (2006) argued that "... exclusive use of community attributes such as species richness will yield little to our mechanistic understanding of invasion patterns in large natural systems." These statements suggest that experimental resource additions could fundamentally alter, or even erase, any negative relationship between diversity and invasibility that existed in isolation.

Understanding the relative importance of native diversity and resource availability is particularly impor- 
tant given current trends and future predictions about effects of global change. Not only are amounts of soil resources increasing due to atmospheric nitrogen deposition (Vitousek et al. 1997, Houghton et al. 2001) but at least in the intermountain West of the United States, rain and snow patterns are also predicted to change (Houghton et al. 2001). At the same time, global climate change may lead to reductions in local species richness (Walther et al. 2002). How changes in soil resources and species diversity will simultaneously influence community susceptibility to invasion is unclear.

Here we consider how invasibility is influenced by the individual and interactive effects of water availability and native plant diversity. We experimentally created native-plant assemblages that varied in species and functional richness and crossed these diversity treatments with water additions, since water is an extremely limiting resource in grasslands of the intermountain West (Sheley et al. 1999). We invaded assemblages with spotted knapweed, Centaurea maculosa, a perennial exotic that occurs at very high densities in grasslands in the intermountain West (Sheley and Petroff 1999). Because spotted knapweed is a "strong invader" (sensu Ortega and Pearson 2005) it represents an excellent test case for exploring the relative strength of factors that can influence invasion resistance.

\section{Methods}

The experiment took place in a fallow field at Fort Missoula (Missoula, Montana, USA). Eight months prior to the initiation of the experiment we tilled and repeatedly treated the field with non-selective herbicide (Roundup; Monsanto, St. Louis, Missouri, USA) to kill agricultural weeds. The field contained no spotted knapweed prior to our experiment, and there was no substantial recruitment of knapweed from a preexisting seed bank during the course of the study. In April 2003 we created 23 unique plant assemblages that varied in species and/or functional richness. Each diversity treatment was crossed factorially with a \pm water treatment with each treatment combination replicated three times (23 diversity treatments $\times 2$ water treatments $\times 3$ replicates $=138$ plots total). Assemblages were weeded continuously to maintain predetermined levels of species and functional richness. Continuously weeding enabled us to remove plants when tiny, thereby minimizing disturbance.

Assemblages were composed of native perennials that commonly co-occur in grasslands in the intermountain West. We created monocultures composed of 11 native species (Table 1) and mixed species assemblages that varied in species richness $(1,2,5,6,8,10,11$, or 16 species) and/or functional richness (one, two, three, four, or six functional groups; Table 1). Plants were assigned to the following functional groups: (1) grasses (three species: Festuca idahoensis, Koelaria macrantha, and Poa sandbergii), (2) very early flowering forbs with a shallow tap root (two species: Dodecatheon pulchellum and Lewisia rediviva), (3) early-flowering rhizomatous forbs (three species: Geum triflorum, Antennaria rosea, and Penstemon procerus), (4) mid-season forbs with woody root crowns (three species: Arnica sororia, Achillea millefolium, and Monarda fistulosa), (5) midseason forbs with spreading rhizomes (three species: Penstemon wilcoxii, Potentilla arguta, and Gaillardia aristata), and (6) late-season forbs with deep tap roots (two species: Aster falcatus and Artemesia frigida). In cases in which a diversity treatment contained only a subset of species from a particular functional group, species from that functional group were randomly assigned. Diversity treatments that contained identical combinations of species and functional richness (e.g., treatments 13 vs. 14,16 vs. 17, etc.; Table 1) varied in functional identity, which was chosen randomly. For logistical reasons, five species (Poa sandbergii, Dodecatheon pulchellum, Lewisia rediviva, Aster falcatus, and Artemesia frigida) were not grown in monoculture or in assemblages with fewer than 16 species.

We created assemblages by transplanting seedlings that were propagated in a greenhouse for 3.5 months prior to outplanting into $3 \times 3 \mathrm{~m}$ plots divided into four $1.3 \times 1.3 \mathrm{~m}$ subplots (separated by $0.2 \mathrm{~m}$ buffer strips). Subplots within plots were planted with identical mixes of native species at the same initial density. Subplots were randomly assigned to be invaded by spotted knapweed (hereafter referred to as "knapweed"), Dalmatian toadflax (Linaria dalmatica), sulfur cinquefoil (Potentilla recta) or remained as uninvaded controls. In the present paper we report on the knapweed-invaded and uninvaded subplots.

Plots were arranged in three blocks separated by $6 \mathrm{~m}$; plots within blocks were separated by $3 \mathrm{~m}$. Natives were planted at an initial density of 32 individuals per subplot and supplemented in April 2004 with an additional 16 individuals per subplot. The ultimate density of species in subplots was higher than planted density, however, due to abundant natural recruitment of seedlings in spring 2005 and 2006 from copious seed production during summer 2004 and 2005.

Three months prior to first invading assemblages, in May 2004, we began applying the water addition treatment. We continued this treatment in 2005 and 2006, after invasion. Plots were watered for one hour each week during May and June via a $1.25 \mathrm{~cm}$ diameter soaker hose that was installed in a zigzag pattern across each plot. We added twice $(5 \mathrm{~cm})$ the long-term monthly average rainfall for these months, which account for $30 \%$ of the $32.5 \mathrm{~cm}$ of precipitation that Missoula Valley receives annually. During weeks of heavy rainfall in May/June 2005 and 2006, we covered control plots with $4.5 \times 4.5 \mathrm{~m}$ clear plastic tarps (light transmittance $80 \%$ ) to preserve treatment differences. Plots were covered on four occasions in 2005 and once in 2006. Tarps were suspended above each plot via elastic cords stretched to fence posts and kept in place for an average of 39 hours each time they were deployed. Because we occasionally 
TABLE 1. Combinations of species richness (SR) and functional richness (FR) used in experimental assemblages.

\begin{tabular}{|c|c|c|c|c|}
\hline Diversity treatment & Community composition & Species & SR & FR \\
\hline 1 & $\mathrm{G}_{1 \mathrm{a}}$ & Festuca idahoensis & 1 & 1 \\
\hline 2 & $\mathrm{G}_{1 \mathrm{~b}}$ & Koelaria macrantha & 1 & 1 \\
\hline 3 & $\mathrm{~F}_{1 \mathrm{a}}$ & Geum triflorum & 1 & 1 \\
\hline 4 & $F_{1 b}$ & Antennaria rosea & 1 & 1 \\
\hline 5 & $\mathrm{~F}_{1 \mathrm{c}}$ & Penstemon procerus & 1 & 1 \\
\hline 6 & $F_{2 a}$ & Arnica sororia & 1 & 1 \\
\hline 7 & $\mathrm{~F}_{2 \mathrm{~b}}$ & Achillea millefolium & 1 & 1 \\
\hline 8 & $\mathrm{~F}_{2 \mathrm{c}}$ & Monarda fistulosa & 1 & 1 \\
\hline 9 & $\mathrm{~F}_{3 \mathrm{a}}$ & Penstemon wilcoxii & 1 & 1 \\
\hline 10 & $F_{3 b}$ & Potentilla arguta & 1 & 1 \\
\hline 11 & $\mathrm{~F}_{3 \mathrm{c}}$ & Gaillardia aristata & 1 & 1 \\
\hline 12 & $\mathrm{G}_{1 \mathrm{a}} \mathrm{G}_{1 \mathrm{~b}}$ & & 2 & 1 \\
\hline 13 & $\mathrm{G}_{1 \mathrm{a}} \mathrm{G}_{1 \mathrm{~b}} \mathrm{~F}_{2 \mathrm{a}} \mathrm{F}_{2 \mathrm{~b}} \mathrm{~F}_{2 \mathrm{c}}$ & & 5 & 2 \\
\hline 14 & $\mathrm{G}_{1 \mathrm{a}} \mathrm{G}_{1 \mathrm{~b}} \mathrm{~F}_{3 \mathrm{a}} \mathrm{F}_{3 \mathrm{~b}} \mathrm{~F}_{3 \mathrm{c}}$ & & 5 & 2 \\
\hline 15 & $\mathrm{G}_{1 \mathrm{a}} \mathrm{G}_{1 \mathrm{~b}} \mathrm{~F}_{2 \mathrm{x}} \mathrm{F}_{3 \mathrm{x}} \mathrm{F}_{3 \mathrm{y}}$ & & 5 & 3 \\
\hline 16 & $\mathrm{G}_{1 \mathrm{a}} \mathrm{G}_{1 \mathrm{~b}} \mathrm{~F}_{1 \mathrm{x}} \mathrm{F}_{1 \mathrm{y}} \mathrm{F}_{2 \mathrm{x}} \mathrm{F}_{2 \mathrm{y}}$ & & 6 & 3 \\
\hline 17 & $\mathrm{G}_{1 \mathrm{a}} \mathrm{G}_{1 \mathrm{~b}} \mathrm{~F}_{2 \mathrm{x}} \mathrm{F}_{2 \mathrm{y}} \mathrm{F}_{3 \mathrm{x}} \mathrm{F}_{3 \mathrm{y}}$ & & 6 & 3 \\
\hline 18 & $\mathrm{G}_{1 \mathrm{a}} \mathrm{G}_{1 \mathrm{~b}} \mathrm{~F}_{1 \mathrm{x}} \mathrm{F}_{1 \mathrm{y}} \mathrm{F}_{2 \mathrm{x}} \mathrm{F}_{3 \mathrm{x}}$ & & 6 & 4 \\
\hline 19 & $\mathrm{G}_{1 \mathrm{a}} \mathrm{G}_{1 \mathrm{~b}} \mathrm{~F}_{1 \mathrm{x}} \mathrm{F}_{2 \mathrm{x}} \mathrm{F}_{2 \mathrm{y}} \mathrm{F}_{3 \mathrm{x}}$ & & 6 & 4 \\
\hline 20 & $\mathrm{G}_{1 \mathrm{a}} \mathrm{G}_{1 \mathrm{~b}} \mathrm{~F}_{1 \mathrm{x}} \mathrm{F}_{1 \mathrm{y}} \mathrm{F}_{2 \mathrm{x}} \mathrm{F}_{2 \mathrm{y}} \mathrm{F}_{3 \mathrm{x}} \mathrm{F}_{3 \mathrm{y}}$ & & 8 & 4 \\
\hline 21 & $\mathrm{G}_{1 \mathrm{a}} \mathrm{G}_{1 \mathrm{~b}} \mathrm{~F}_{1 \mathrm{a}} \mathrm{F}_{1 \mathrm{~b}} \mathrm{~F}_{1 \mathrm{c}} \mathrm{F}_{2 \mathrm{a}} \mathrm{F}_{2 \mathrm{~b}} \mathrm{~F}_{2 \mathrm{c}} \mathrm{F}_{3 \mathrm{x}} \mathrm{F}_{3 \mathrm{y}}$ & & 10 & 4 \\
\hline 22 & $\mathrm{G}_{1 \mathrm{a}} \mathrm{G}_{1 \mathrm{~b}} \mathrm{~F}_{1 \mathrm{a}} \mathrm{F}_{1 \mathrm{~b}} \mathrm{~F}_{1 \mathrm{c}} \mathrm{F}_{2 \mathrm{a}} \mathrm{F}_{2 \mathrm{~b}} \mathrm{~F}_{2 \mathrm{c}} \mathrm{F}_{3 \mathrm{a}} \mathrm{F}_{3 \mathrm{~b}} \mathrm{~F}_{3 \mathrm{c}}$ & & 11 & 4 \\
\hline 23 & $\mathrm{G}_{1 \mathrm{a}} \mathrm{G}_{1 \mathrm{~b}} \mathrm{G}_{1 \mathrm{c}} \mathrm{F}_{1 \mathrm{a}} \mathrm{F}_{1 \mathrm{~b}} \mathrm{~F}_{1 \mathrm{c}} \mathrm{F}_{2 \mathrm{a}} \mathrm{F}_{2 \mathrm{~b}} \mathrm{~F}_{2 \mathrm{c}} \mathrm{F}_{3 \mathrm{a}} \mathrm{F}_{3 \mathrm{~b}} \mathrm{~F}_{3 \mathrm{c}} \mathrm{F}_{4 \mathrm{a}} \mathrm{F}_{4 \mathrm{~b}} \mathrm{~F}_{5 \mathrm{a}} \mathrm{F}_{5 \mathrm{~b}}$ & & 16 & 6 \\
\hline
\end{tabular}

Notes: Functional groups are grasses $\left(\mathrm{G}_{1}\right.$, species a, b, and c [Poa sandbergii]), early-season rhizomatous forbs $\left(\mathrm{F}_{1}\right.$, species a-c), late-season rhizomatous forbs $\left(\mathrm{F}_{2}\right.$, species a-c), and mid-season tap-rooted forbs $\left(\mathrm{F}_{3}\right.$, species a-c). The 16-species assemblage (treatment 23) contains the additional grass (Poa sandbergii) and forbs from two additional functional groups: perennial spring ephemerals $\left(\mathrm{F}_{4 \mathrm{a}, \mathrm{b}} ;\right.$ Dodecatheon pulchellum and Lewisia rediviva) and late-summer, tap-rooted species $\left(\mathrm{F}_{5 \mathrm{a}, \mathrm{b}} ;\right.$ Aster falcatus and Artemesia frigida). These species were not grown in monoculture. Where specific species identity is not shown (i.e., where there is an " $x$ " or " $y$ " subscript denoting species identity), for each replicate of that treatment the species was drawn at random from the pool of three species from that particular functional group.

limited rainfall in control plots, we refer to them as "dry plots" and we refer to plots receiving supplemental water as "wet plots."

In this paper we define invasibility as knapweed abundance in assemblages that received identical initial propagule pressure. To emulate invasion by knapweed, $10.71 \mathrm{~g}$ and $5.35 \mathrm{~g}$ of knapweed seed was applied to the center $1 \mathrm{~m}^{2}$ of subplots in September 2004 and 2005, respectively. In total, this corresponded to $\sim 7500$ seeds added to each assemblage (J. Maron and M. Marler, unpublished data). A single knapweed individual can produce upwards of 5000 seeds (A. Stanley, unpublished manuscript). We collected knapweed seeds for this experiment from local infestations and took care to collect seed heads that were undamaged by biocontrol agents. Field seed addition experiments indicated that the viability of these seeds was quite high (J. Maron and M. Marler, unpublished data).

\section{Data collection}

Within a $1-\mathrm{m}^{2}$ quadrat placed in the center of all mixed-species invaded assemblages, we (1) visually estimated the percentage cover of all native plants and the percentage cover of bare ground in April 2005; (2) counted the number of knapweed flowering stems and small nonflowering individuals in mid-September 2005 and 2006; (3) counted the number of newly emerged knapweed seedlings in mid-September 2005 (by assigning seedlings to abundance classes that were in multiples of 10 [i.e., $0-10$ individuals, $11-20,21-30$, etc.]) and in late April 2006; and (4) counted the number of seed heads produced in each mixed-species assemblage in September 2005. In 2006 there were too many seed heads to count individually so we counted seed heads in a subset of subplots $(n=40)$ and used the regression between number of bolting stems and total number of seed heads per subplot $\left(R^{2}=0.81, F_{1,38}=139, P<\right.$ $0.001)$ to estimate seed head production in subplots in which only flowering stems were counted. In late April/early May 2006 we also recorded the presence/absence of all native plants within a central $1-\mathrm{m}^{2}$ quadrat placed in each uninvaded and invaded subplot. We restricted our sampling to the central $1 \mathrm{~m}^{2}$ of each subplot to avoid possible edge effects. In August 2006 we counted, cut, and bagged all flowering knapweed stems within all monocultures and bare plots. Harvested stems were dried at $60^{\circ} \mathrm{C}$ until they reached a constant mass and then weighed.

From mid-May to late July 2005 we measured soil moisture in uninvaded and knapweed-invaded subplots approximately every 10 days. Soil moisture was measured with a TRIME FM time domain reflectometer (TDR) probe (Mesa Systems, Medfield, Massachusetts, USA) that was inserted into $5.1 \mathrm{~cm}$ diameter PVC access pipes that were installed in summer 2003 or 2004. Soil moisture was measured at $5-15 \mathrm{~cm}$ and $35-50 \mathrm{~cm}$ depths. We quantified soil nitrogen by determining the amount of $\mathrm{NO}_{3}{ }^{-}$and $\mathrm{NH}_{4}{ }^{+}$sorbed to ion exchange resin capsules 
(containing $1 \mathrm{~g}$ of ionic resin; Unibest, Bozeman, Montana, USA) through the growing season. Resin capsules were buried in haphazardly selected locations in the middle of each subplot. In 2005, one resin capsule was buried 5-10 cm deep in each uninvaded subplot in late April and excavated in early August. In 2006 we buried two resin capsules in the middle of each uninvaded and invaded subplot in late April and excavated these at the end of the growing season (midJuly). In both years, immediately after excavation resin capsules were transported to the laboratory on ice and extracted by bathing capsules in three sequential onehour rinses in $10 \mathrm{~mL}$ of $2 \mathrm{~mol} / \mathrm{L} \mathrm{KCl}$. Capsules were gently shaken on a shaker table during each rinse, after which $\mathrm{KCl}$ extracts were decanted to create a total extract volume of $30 \mathrm{~mL}$. Extracts were then analyzed for $\mathrm{NH}_{4}{ }^{+}$and $\mathrm{NO}_{3}{ }^{-}$on an Autoanalyzer III (Bran Luebbe, Chicago, Illinois, USA). For 2006 data, we calculated the mean nitrogen values from the two resin capsules buried in each subplot and used these values in analyses.

In early July 2006, we also measured photosynthetically active solar radiation (PAR) within uninvaded assemblages. We held an $86.5 \mathrm{~cm}$ long linear ceptometer (AccuPar-LP80, Decagon Devices, Pullman, Washington, USA) diagonally across each subplot and recorded PAR above and below (6-8 $\mathrm{cm}$ above ground level) the canopy.

\section{Statistical methods}

We used ANCOVA to determine how block, water treatment, and native species or functional richness influenced the number of knapweed (1) flowering stems and (2) small nonflowering individuals that established in assemblages as of September 2006, (3) cumulative seed heads produced per plot across 2005 and 2006, and (4) seedlings in September 2005 or April 2006 (all response variables square-root transformed). Since seedling abundance in 2005 was estimated by assigning seedlings to classes based on multiples of 10 , we used the midpoint of each class as the estimate of seedling number. Water treatment was a fixed factor, block was a random factor, and either realized functional richness or realized species richness were used as continuous covariates. We added together the number of flowering stems and nonflowering individuals to characterize invasion success (as opposed to the total number of knapweed genets per subplot) for two reasons. First, individual knapweed plants put out so many flowering stems in some assemblages that it was difficult to distinguish among genetically distinct individuals. More importantly, total stem number was a better indicator of overall exotic cover and biomass than simply the number of flowering genets (J. Maron and M. Marler, unpublished data). Second, although small nonflowering plants contributed minimally to overall cover, these individuals represent a pool of colonists that are available to flower in the future.
Throughout the experiment, native functional and species richness in some assemblages changed. Thus, the exact native diversity level that knapweed experienced in some assemblages depended on the year of invasion. To be conservative, in analyses we used the species/functional richness of assemblages as of April 2006 (i.e., hereafter referred to as realized species or functional richness) rather than using the initial (planted) functional or species richness. Realized species and functional richness in mixed-species assemblages was strongly correlated with the initial intended species or functional richness (Pearson $r=0.96-0.98$ ). We first tested models that included the water treatment $\times$ diversity interaction, since this tests whether water addition altered the slope of any diversity-invasibility relationship. However, this interaction term was never significant; thus we report results from models with main effects only. To eliminate the possibility of highly invasible monocultures driving a negative diversityinvasibility relationship (Wardle 2001), we excluded monocultures in tests for effects of diversity on invasibility. To ensure that effects of diversity on invasibility were not due to changes in native cover or percentage of bare ground across diversity treatments, we used ANCOVA (as above) to determine how percentage of bare ground and percentage of native plant cover (both arcsine square-root transformed) in mixed species invaded assemblages varied as a function of realized species richness and water treatment in April 2005 , during the first spring of invasion.

To examine how the biomass of flowering knapweed stems (square-root transformed) varied among native monocultures, we used two-way ANOVA with native identity and water treatment as factors. Significance differences between natives were subsequently determined by a post hoc Tukey's hsd test. We omitted Arnica sororia monocultures from this analysis since the density of $A$. sororia in these plots was very sparse (cover, $17 \% \pm$ 4.7\%; mean $\pm \mathrm{SE}$ ). Since Achillea millefolium monocultures were less invaded that several others, we ran an additional analysis to determine whether the effects of species diversity remained significant after the presence/ absence of $A$. millefolium in diverse plots was accounted for. We used an ANCOVA to test effects of block, water treatment, presence/absence of $A$. millefolium, and the $A$. millefolium $\times$ water treatment interaction. Realized species richness was used as a covariate in this model and the total number of knapweed flowering stems plus small individuals (square-root transformed) was the response variable. The realized species richness $\times A$. millefolium interaction was not significant so this was dropped from the model.

Within uninvaded assemblages, we used ANCOVAs to determine how block, water treatment, and realized species richness influenced (1) soil nitrogen availability in 2005 and 2006 (log-transformed) and (2) light availability in 2006 (calculated as the percentage reduction in PAR from above to below the canopy, 

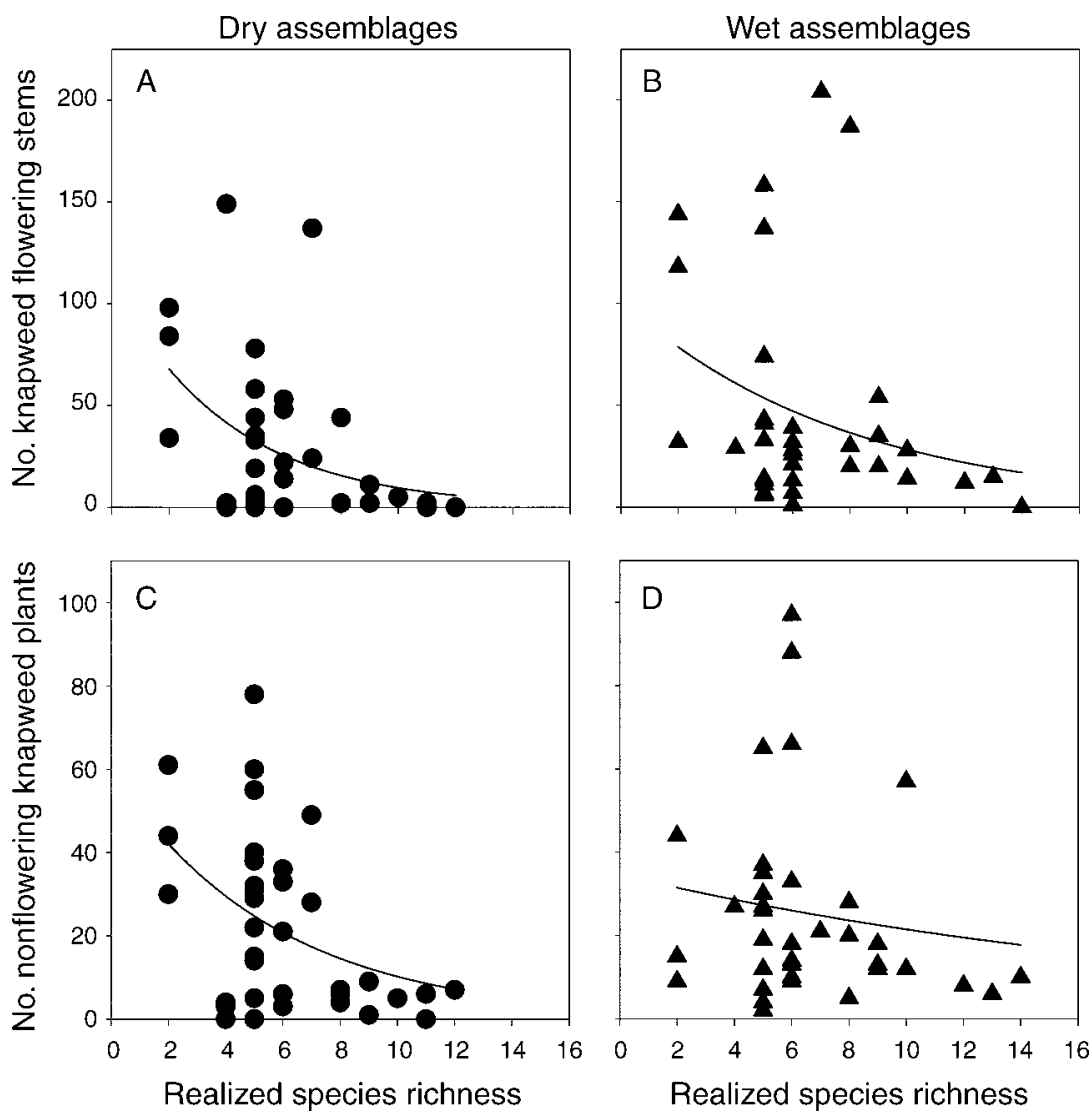

FIG. 1. Effect of species richness and water addition on (A, B) the number of flowering stems and (C, D) the number of nonflowering individuals of spotted knapweed (Centaurea maculosa). Curves represent the best fit through data points. Assemblage refers to the group of plants in each experimental subplot. Water was added to "wet" assemblages every week in May and June via soaker hose. Realized species richness is the actual number of species in an assemblage rather than the number of species planted. See Methods for details.

arcsine square-root transformed). For soil nitrogen, we ran separate ANOVAs for 2005 and 2006 since species richness changed in some assemblages across years. In all tests the diversity $\times$ water treatment interaction was not significant, thus reported models are those without interaction terms. To determine how native diversity and water additions influenced soil moisture, we performed separate repeated-measures ANCOVAs on arcsine square-root transformed soil moisture data taken across the 2005 and 2006 growing seasons.

Finally, we used multiple (backward) stepwise regression to examine the relative effects of native diversity and resource availability on knapweed abundance. We ran regressions for wet and dry assemblages separately. In these analyses, the number of bolting knapweed stems plus small individuals (square-root transformed) was the response variable and realized species richness, the average amount of soil nitrate and ammonium in 2006, the average soil moisture at shallow $(5-15 \mathrm{~cm})$ and deep $(35-50 \mathrm{~cm})$ soil levels across the 2006 season, and the percentage reduction in PAR (arcsine squareroot transformed) were predictor variables.

\section{RESUlts}

Models using realized species richness and realized functional richness as covariates produced $R^{2}$ values that were within $1-2 \%$ of one another. Since in almost all cases models using realized species richness accounted for slightly more variation than did models using realized functional richness, we report these results only (but see Appendix for a comparison of $R^{2}$ values for different models).

Results across invaded assemblages revealed several clear patterns. First, there was a strong negative effect of native diversity on invasibility. The number of knapweed flowering stems $\left(F_{1,67}=9.1, P<0.003\right.$; Fig. 1A, B), nonflowering individuals $\left(F_{1,67}=7.3, P<0.009\right.$; Fig. $1 \mathrm{C}, \mathrm{D})$, and the cumulative $(2005+2006)$ number of seed heads produced in each assemblage $\left(F_{1,67}=9.2, P\right.$ $<0.001)$ all declined with increasing native diversity. In mixed-species subplots that we invaded, there was no effect of realized species richness on percentage of bare ground $\left(F_{1,67}=0.48, P=0.49\right)$ or on native cover $\left(F_{1,67}=\right.$ $0.013, P=0.91)$, suggesting that the negative effects of 

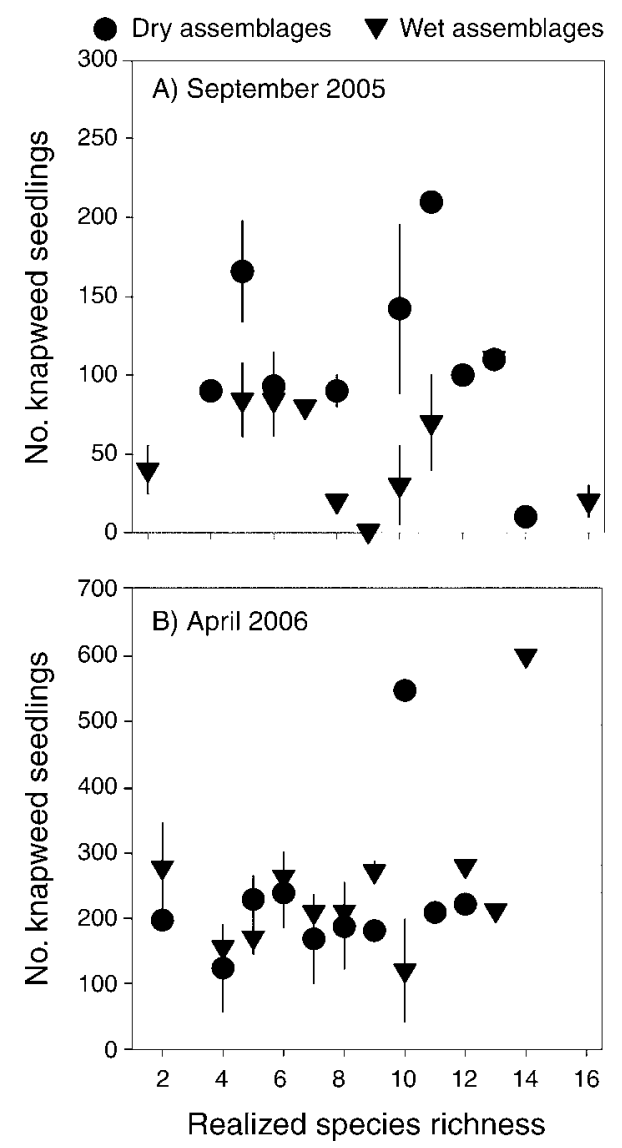

FIG. 2. Effect of species richness and water addition on knapweed seedling abundance in (A) September 2005 and (B) April 2006 (mean \pm SE). Assemblage refers to the group of plants in each experimental subplot. Water was added to "wet" assemblages every week in May and June via soaker hose. Realized species richness is the actual number of species in an assemblage rather than the number of species planted. See Methods for details.

species richness on invasion were unlikely due to fewer openings for colonization in more diverse assemblages.

Second, experimental water addition increased invasibility. The number of flowering stems $\left(F_{1,67}=6.8, P<\right.$ 0.012; Fig. 1) and the cumulative number of seed heads in each subplot $\left(F_{1,67}=6.8, P<0.012\right.$; Fig. 1$)$ were greater in wet vs. dry assemblages. Water addition had no effect on the number of nonflowering knapweed in assemblages $\left(F_{1,67}=2.1, P=0.15\right)$. Finally, water addition did not fundamentally change the slope of the relationship between diversity and invasibility (Fig. 1). In a full model that tested all interactions, the water treatment $\times$ realized species richness interaction was not significant for the total number of flowering knapweed stems $\left(F_{1,66}=0.34, P=0.56\right)$, the number of nonflowering individuals $\left(F_{1,66}=2.4, P=0.13\right)$, or the cumulative number of seed heads produced per subplot $\left(F_{1,66}=0.33, P=0.57\right)$.
A negative diversity-invasibility relationship might arise because diverse assemblages inhibit exotic recruitment. We found no significant effect of species richness on knapweed seedling recruitment in fall $2005\left(F_{1,67}=\right.$ $2.4, P=0.12$; Fig. 2$)$ or spring $2006\left(F_{1,67}=2.1, P=0.16\right.$; Fig. 2). Knapweed recruitment in fall 2005 was actually lower in wet vs. dry plots $\left(F_{1,66}=13.6, P<0.0001\right.$; Fig. $2)$, although this was not the case in spring $2006\left(F_{1,67}=\right.$ $0.26, P=0.61$; Fig. 2).

One mechanism by which diversity might resist invasion is through a "sampling effect." This occurs if one native in particular is a good competitor against exotics and if this species is by chance more likely to occur in high- vs. low-diversity plots. To determine whether this was the case, we compared the biomass of flowering knapweed stems across native monocultures. Achillea millefolium monocultures supported significantly less knapweed biomass than did monocultures of several other natives (two-way ANOVA, $F_{9,37}=2.8, P<$ 0.015; Fig. 3). Interestingly, water addition did not affect knapweed invasion of monocultures (ANOVA, $F_{1,37}=$ $2.1, P=0.15$ ), nor was there a water addition $\times$ native identity interaction (ANOVA, $F_{9,37}=0.42, P=0.92$ ). In mixed-species assemblages, those containing $A$. millefolium contained fewer knapweed flowering stems plus small individuals than those without A. millefolium (ANCOVA, $F_{1,66}=19.3, P<0.0001$ ). However, the negative effect of species richness on knapweed abundance was significant even after variation due to $A$. millefolium presence/absence was accounted for (ANCOVA, $F_{1,66}=4.6, P<0.036$ ), and in a separate model, the $A$. millefolium $\times$ realized species richness interaction was not significant (ANCOVA, $F_{1,64}=0.17, P=0.90$ ). Moreover, if diversity effects were entirely driven by the strong competitive impacts of $A$. millefolium, then one might expect monocultures of $A$. millefolium to be more resistant to knapweed invasion than diverse assemblages. This was not the case. The average number of flowering knapweed stems in A. millefolium monocultures was $34.5 \pm 26.4$. In contrast, in mixed species assemblages containing $>10$ species, the number of flowering knapweed stems per subplot averaged $8.4 \pm$ 3.2 (ANOVA, $F_{1,67}=10.6, P<0.0003$ ). Finally, to rule out the possibilities that (1) one of the five species in the 16-species assemblages that were not grown in monoculture was a particularly potent competitor against knapweed or (2) high resistance in the most diverse assemblages drove the overall negative diversity-invasibility relationship, we analyzed effects of diversity excluding the highest diversity plots. In this more restricted analysis, the effects of species diversity on the number of knapweed flowering stems plus small individuals was still significant (ANCOVA, $F_{1,61}=5.2, P$ $<0.03)$.

Another mechanism by which diversity can resist invasion is through greater resource preemption in more diverse assemblages. In uninvaded assemblages in 2005 , plant-available soil nitrogen levels $\left(F_{1,130}=6.5, P<\right.$ 


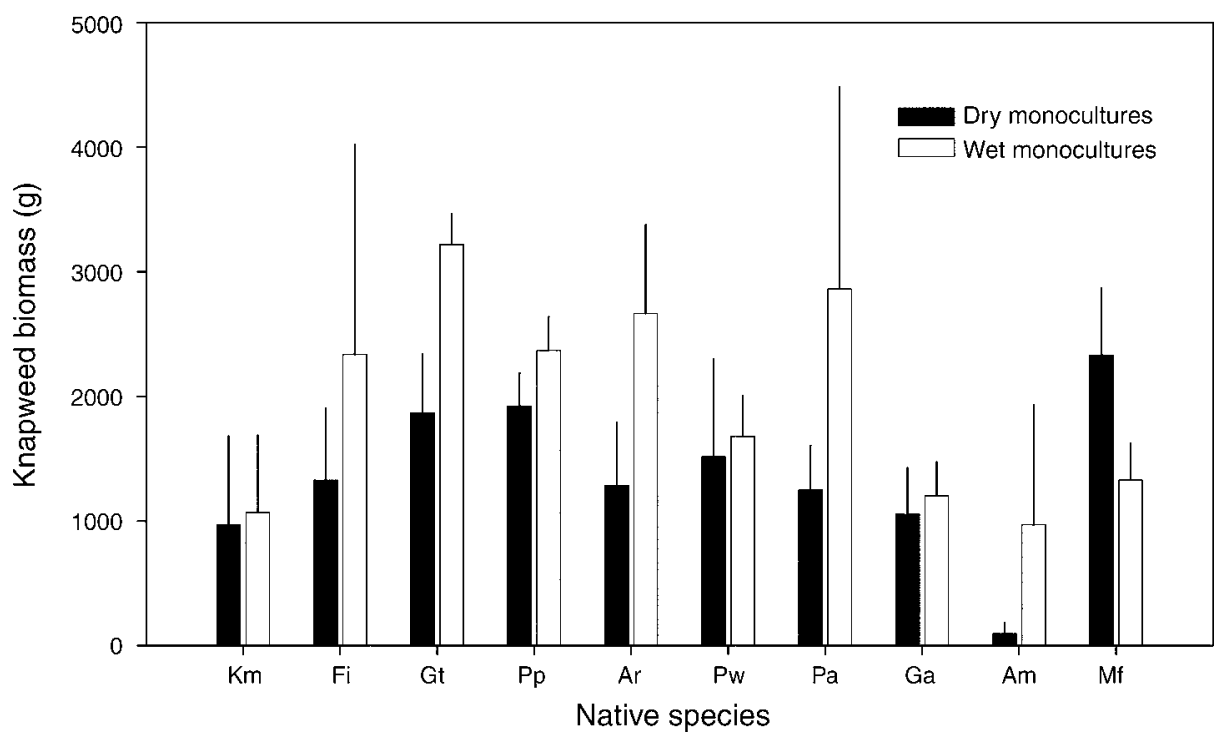

FIG. 3. Biomass (mean $+\mathrm{SE}$ ) of knapweed flowering stems in dry and wet native monocultures. Water was added to "wet" assemblages every week in May and June via soaker hose. See Methods for details. Abbreviations for native species are: Km, Koelaria macrantha; Fi, Festuca idahoensis; Gt, Geum triflorum; Pp, Penstemon procerus; Ar, Antennaria rosea; Pw, Penstemon wilcoxii; Pa, Potentilla arguta; Ga, Gaillardia aristata; Am, Achillea millefolium; Mf, Monarda fistulosa. Knapweed biomass was significantly lower in $A$. millefolium monocultures (mean $=532 \mathrm{~g}$ ) than in monocultures of Geum triflorum (mean $=2556 \mathrm{~g}$; Tukey post hoc test, $P<0.008$ ) and Penstemon procerus (mean $=2144 \mathrm{~g}$; Tukey post hoc test, $P<0.022$ ) and marginally lower in $A$. millefolium monocultures than in monocultures of Antennaria rosea (mean $=1974 \mathrm{~g}$; Tukey post hoc test, $P=0.06)$ and $M o n a r d i a$ fistulosa $($ mean $=1831 \mathrm{~g}$; Tukey post hoc test, $P<0.07)$. All other native monocultures were not significantly different in invasion resistance.

$0.013)$ and shallow soil moisture (5-15 cm depth) declined with increasing species richness (repeatedmeasures [rm]ANOVA, $\left.F_{1,132}=5.4, P<0.023\right)$. Realized species richness had a marginally significant effect on deeper soil moisture $(35-50 \mathrm{~cm}$ depth, rmANOVA, $\left.F_{1,133}=3.5, P<0.065\right)$. In 2006, the same general patterns held; plant-available nitrogen $\left(F_{1,130}=\right.$ 4.99, $P<0.027$ ) and soil moisture (rmANOVA, shallow, $F_{1,126}=3.6, P<0.06$; deep, $F_{1,116}=4.0, P<$ 0.048 ) declined significantly with increasing species richness. In both years average soil moisture across all dry plots declined during the growing season (2005 shallow, $R^{2}=0.96, F_{1,3}=66.6, P<0.0039 ; 2005$ deep, $R^{2}=0.96, F_{1,3}=72.4, P<0.004 ; 2006$ shallow, $R^{2}=$ $0.98, F_{1,4}=176, P<0.0001 ; 2006$ deep, $R^{2}=0.67, F_{1,4}=$ $8.1, P<0.047)$.

Experimental water addition increased soil moisture in both years (rmANOVA, 2005, shallow, $F_{1,132}=109$, $P<0.0001$, and deep, $F_{1,133}=60.3, P<0.0001 ; 2006$, shallow, $F_{1,126}=43.0, P<0.0001$, and deep, $F_{1,116}=$ 19.5, $P<0.0001)$ and also increased plant-available nitrogen $\left(F_{1,130}=33.4, P<0.0001\right.$ and $F_{1,131}=4.8, P<$ 0.032 for 2005 and 2006 , respectively). The percentage of ambient PAR that was available beneath the canopy of each assemblage also declined with increasing species richness in 2006, the only year in which this was measured (ANOVA, $\left.F_{1,67}=5.4, P=0.024\right)$. Water addition decreased available PAR (ANOVA, $F_{1,67}=8.9$, $P<0.005)$, but did not alter the negative relationship between species richness and available PAR (i.e., water treatment $\times$ species richness was not significant).

In the stepwise multiple regression that included species richness and levels of soil, light, and nitrogen in invaded dry assemblages, there were significant negative effects of native species richness and significant positive effects of nitrate and deep soil moisture on knapweed abundance (Table 2). Effects of ammonium and light were not significant predictors of knapweed abundance. In wet plots, there were again significant negative effects of native-species richness on knapweed abundance, but in contrast to dry plots, a significant positive effect of light reduction on knapweed abundance (Table 2).

\section{Discussion}

Although previous studies have shown that native plant diversity can resist invasion (Levine 2000, Naeem et al. 2000, Prieur-Richard et al. 2000, Symstad 2000, Dukes 2002, Kennedy et al. 2002, Fargione et al. 2003, van Ruijven et al. 2003, Zavaleta and Hulvey 2004), several lingering concerns have led to questions regarding how robust these results might be. First, some have argued that negative effects of diversity on invasibility are often driven by highly invaded monocultures. The argument here is that inclusion of monocultures in analyses of effects of diversity on invasibility could skew results in favor of diversity strongly influencing invasibility when in fact these effects might be extremely weak 
TABLE 2. Stepwise (backward) multiple regression of total spotted knapweed (Centaurea maculosa) abundance (flowering stems plus small individuals, square-root transformed) against species richness and resource levels in dry and wet assemblages.

\begin{tabular}{|c|c|c|c|c|c|c|c|c|}
\hline \multirow[b]{2}{*}{ Variable } & \multicolumn{4}{|c|}{ Dry assemblages } & \multicolumn{4}{|c|}{ Wet assemblages } \\
\hline & Coefficient & SE & $F$ & $P$ & Coefficient & SE & $F$ & $P$ \\
\hline Realized species richness & -0.751 & 0.192 & -3.909 & 0.001 & -0.475 & 0.161 & 8.640 & 0.006 \\
\hline Average shallow soil moisture & -0.666 & 0.378 & -1.761 & 0.088 & 0.127 & & 0.521 & 0.476 \\
\hline Average deep soil moisture & 0.49 & 0.208 & 2.351 & 0.026 & 0.095 & & 0.292 & 0.593 \\
\hline $\mathrm{NH}_{4}^{+}+\mathrm{P}^{+}$ & -0.103 & & 0.298 & 0.589 & -0.016 & & 0.009 & 0.927 \\
\hline $\mathrm{NO}_{3}^{-}$ & 0.372 & 0.148 & 2.507 & 0.018 & 0.030 & & 0.028 & 0.868 \\
\hline Reduction in PAR (\%) & 0.040 & & 0.046 & 0.833 & 8.31 & 2.49 & 11.19 & 0.002 \\
\hline
\end{tabular}

Notes: Final model, dry assemblages $\left(R^{2}=0.49, F_{4,30}=7.0, P<0.000\right)$, wet assemblages $\left(R^{2}\right.$ for entire model $=0.35 ; F_{2,33}=8.8$, $P<0.001)$. Each variable has $\mathrm{df}=1,35$.

or even nonexistent (Wardle 2001). Second, since experimental assemblages have often been constructed in small PVC pipes, on tiles, or in tiny plots that are often less that $0.15 \mathrm{~m}^{2}$ (Stachowicz et al. 1999, Levine 2000, Lyons and Schwartz 2001, Dukes 2002, Zavaleta and Hulvey 2004), or the effects have been evaluated at the extreme neighborhood scale (Naeem et al. 2000), the question has arisen about how these small-scale effects might translate to larger spatial scales. Third, diversityinvasibility experiments have been criticized because researchers have used natives as "model invaders" rather than invading experimental assemblages with exotics (e.g., Knops et al. 1999, Lavorel et al. 1999, Symstad 2000). If native "model invaders" are less potent competitors with established natives than are exotics, then results using natives as "model invaders" may be suspect (Stachowicz et al. 2002). Fourth, some have argued that negative effects of diversity on invasibility arise entirely from a sampling effect, whereby increasing resistance to invasion at higher levels of diversity is entirely due to the increasing probability of diverse mixtures containing a highly competitive native (Wardle 2001). Finally, it has been unclear how strong diversity effects might be in the face of other components of environmental variation. Few studies have quantitatively evaluated the importance of diversity relative to resource supply or other factors known to influence invasibility in isolation (Levine and D'Antonio 1999). To some extent, these potential shortcomings are a natural product of the fact that experimental tests of Elton's (1958) seminal idea are still in their infancy and work in this area is still evolving.

We found robust negative effects of diversity on invasibility, despite using a strong invader (sensu Ortega and Pearson 2005). The effects of native diversity remained strong even when resource levels (light, soil moisture, and soil nutrients) were included as predictor variables in multiple regression models. In some previous studies, the significant effects of diversity diminished when resource levels were included in statistical models testing effects on invasibility (Knops et al. 1999). In other studies, diversity effects remain significant but resource levels are poor predictors of invader abundance (van Ruijven et al. 2003).
A key question is where in the invasion process biotic resistance might be most important (Levine et al. 2004). We found that biotic resistance did not prevent knapweed seedling establishment, but rather had strong effects on the subsequent fate of those seedlings (likely through resource competition). One reason why knapweed recruitment may be unaffected by resident native diversity is that knapweed seed germinates abundantly in fall, when many native species are dormant. Although some native species in our experiment germinate in fall, none germinate as profusely as knapweed (J. Maron and M. Marler, unpublished data). This difference in "germination niche" appears to be an important contributor to knapweed's invasiveness.

Native species and functional richness had very similar overall effects on invasibility and resource levels (Appendix). However, these two components of diversity were strongly correlated across our experimental assemblages (invaded subplots, Pearson $r=0.84$; uninvaded subplots, $r=0.87$ ). As such, we may have had limited power to fully disentangle their independent effects. To a certain extent, this will always be the case when species richness varies strongly across assemblages. However, when species richness has been held constant and functional richness has been manipulated in isolation, functional richness has been shown to be effective in resisting invasion (Prieur-Richard et al. 2000, Symstad 2000, Fargione et al. 2003).

Experimental enhancements of resources (soil moisture and through this manipulation, plant-available nitrogen) increased invasion and thus worked in opposition to the effects of diversity. Yet despite increasing invader establishment, resource enhancement did not change the negative relationship between diversity and invasibility. Thus, unlike other studies that have revealed weak or nonexistent effects of diversity relative to propagule pressure (Levine 2000, Von Holle and Simberloff 2005, Thomsen et al. 2006), we found that the effects of diversity were surprisingly robust in the face of high levels of both soil nitrogen and water. These results have several implications. First, counter to some suggestions in the literature (Davis et al. 2000, Renne et al. 2006), resource availability does not always have primacy over diversity in predicting 
invasibility. This implies that diverse native systems may offer invasion resistance even under enhanced resource availability predicted to occur given global climate change (Vitousek et al. 1997, Sheley et al. 1999; Vilà et al. 2006). Second, our results suggest that there may be some practical ways that diversity can be manipulated in restoration contexts. Increasingly, herbicides are used to control dense populations of exotics, which can also decrease native diversity. While direct effects of herbicides can temporarily decrease exotic abundance, exotics often re-invade, requiring further herbicide applications. One way to break this spray-invade-spray cycle might be to reseed areas from which exotics have been reduced with diverse mixtures of native seed. This rationale, of course, assumes that results from small-scale studies such as ours are applicable to restoration activities that might occur over larger spatial scales. In opposition to results such as ours that occur at small spatial scales, larger scale correlative studies often show positive associations between native diversity and exotic diversity/cover (Stohlgren et al. 1999, 2003, 2006). These conflicting results may be related to the differing spatial scales of these studies (Davies et al. 2005) or to differences in how particular exotics respond to diversity (Ortega and Pearson 2005). As well, even at small spatial scales, the relationship between native diversity and exotic abundance can be negative when considering abundance of strong invaders (i.e., exotics that occur at high density), such as spotted knapweed, but positive for native diversity vs. the abundance of weak invaders (those that occur at lower cover; Ortega and Pearson 2005).

The facilitative effects of resource addition on invasion that we found have also been demonstrated in both small-scale experiments (Davis and Pelsor 2001, Thomsen et al. 2006) and in large-scale correlative studies. For example, Stohlgren et al. (1999) found "at the plot and landscape scales, areas of high soil fertility and water holding capacity were particularly invasible." Foster et al. (2002) found that more diverse grassland plots were more heavily invaded and that resource availability explained a greater percentage of the variance in invasibility than did species diversity. In our experiment, water supplementation not only increased soil moisture, but it also increased plantavailable soil nitrogen (likely by stimulating microbial activity) and decreased PAR below the canopy (because watering stimulated aboveground plant productivity). The measured effects of water addition on invasion are probably conservative since water was added to assemblages during spring, when rain is frequent and the soil is relatively moist. By experimentally making a wet time of year wetter, our goal was to determine how increasing soil moisture within this range of natural variability might influence invasion dynamics. Had we continued to add water to assemblages for a longer period in summer, the effects probably would have been more dramatic, although biologically unrealistic. Inter- estingly, current global climate models predict that western Montana may experience wetter springs under global change (Houghton et al. 2001). If true, then our results suggest that this will increase the vulnerability of communities to plant invasion.

Through what mechanism might diversity resist invasion? It is unlikely that our results were entirely driven by a sampling effect. Although assemblages containing $A$. millefolium were less invaded than those without this species, even after effects of $A$. millefolium were statistically accounted for we still found strong negative effects of diversity. Furthermore, more diverse assemblages were less invaded than $A$. millefolium monocultures, which presumably would not be the case if diversity effects were overwhelmingly driven by this one species. Instead, as theory predicts (MacArthur 1970, Tilman 2004), it is likely that diversity inhibited invasion because resource availability declined with increasing diversity. In uninvaded subplots, light, water, and nitrogen availability all declined with increasing diversity. Furthermore, within invaded assemblages some resource levels (nitrate and soil moisture in dry assemblages, light in wet assemblages) were positively associated with knapweed abundance. The fact that in dry assemblages nitrate and deep soil moisture best predicted knapweed invasion whereas in wet assemblages light availability best predicted knapweed invasion indicates that at high levels of resource availability (i.e., elevated soil moisture, and through this treatment, soil nitrate and ammonium), competition for belowground resources shifted to competition for light. As in other diversity-invasibility experiments, this suggests that resource preemption played a role in our results (Kennedy et al. 2002, Fargione et al. 2003).

An important question is whether diverse assemblages that experience high resource supply can continue to resist invasion in the future. It may be that over longer time periods, particular natives will become competitively superior under high resource conditions (Al-Mufti et al. 1977). This could drive down native diversity and thus feed back to decrease overall invasion resistance. Alternatively, if high levels of diversity and resource supply maximize productivity (Hooper et al. 2005), and if the competitiveness of natives is maximized at high levels of productivity (Grime 1973, Huston 1979), then increased resource supply and diversity should synergistically increase invasion resistance (Wardle 2001). Our long-term aim is to determine which of these scenarios might occur. Quantifying the nature of feedbacks between resource levels, productivity, and native plant diversity will be essential for determining both long-term invasion resistance and the overall impact that exotics have on natives. Examining invasions in light of these dynamic feedbacks may also help reconcile results from research at smaller spatial scales, such as that performed in this study, to those at larger spatial scales, where there are often positive associations between native diversity 
and exotic diversity or cover (Stohlgren et al. 1999, 2006).

\section{ACKNOWLEDGMENTS}

We thank Pamela Kittelson, Thomas Martin, Elliott Parsons, Dean Pearson, Montse Vilà, Jennifer Williams, and two anonymous reviewers for helpful comments on the manuscript. Thanks to Sam Andresky, Brandon Barr, Cedar Brant, Jessica Brewer, Bryce Christians, Kate Goodwin, McLain Johnson, Alexis Jones, Sara LaFont, Kathy Mareib, Melissa Maggio, Michael Pecora, Clarice Peña, Rebbeca Richter, Amanda Roberson, Steffany Rogge, Jamie Schmidt, Yoshimi Shimizu, Morgan Valliant, Yafei Wang, and Marijka Wessner for terrific field assistance. The Montana Conservation Corps and Prairie Keepers public outreach project volunteers helped set up experimental plots. This work was supported by a grant from the Montana Weed Trust fund and NSF DEB0296175 to J. Maron and M. Marler and NSF OPP-0296208 to J. Maron.

\section{Literature Cited}

Aerts, R., and F. Berendse. 1988. The effect of increased nutrient availability on vegetation dynamics in wet heathlands. Vegetatio 76:63-69.

Al-Mufti, M. M., C. L. Sydes, S. B. Furness, J. P. Grime, and S. R. Band. 1977. A quantitative analysis of shoot phenology and dominance in herbaceous vegetation. Journal of Ecology 65:759-791.

Case, T. J. 1990. Invasion resistance arises in strongly interacting species-rich model competitive systems. Proceedings of the National Academy of Sciences (USA) 87:96109614.

D'Antonio, C. M., and P. M. Vitousek. 1992. Biological invasions by exotic grasses, the grass/fire cycle, and global changes. Annual Review of Ecology and Systematics 23:6387.

Davies, K. F., P. Chesson, S. Harrison, B. Inouye, B. A. Melbourne, and K. J. Rice. 2005. Spatial heterogeneity explains the scale dependence of native-exotic diversity relationship. Ecology 86:1602-1610.

Davis, M. A., J. P. Grime, and K. Thompson. 2000. Fluctuating resources in plant communities: a general theory of invasibility. Journal of Ecology 88:528-534.

Davis, M. A., and M. Pelsor. 2001. Experimental support for a resource-based mechanistic model of invasibility. Ecology Letters 4:421-428.

Dukes, J. S. 2002. Species composition and diversity affect grassland susceptibility and response to invasion. Ecological Applications 12:602-617.

Elton, C. S. 1958. The ecology of invasions. Methuen, London, UK.

Fargione, J., C. S. Brown, and D. Tilman. 2003. Community assembly and invasion: an experimental test of neutral versus niche processes. Proceedings of the National Academy of Sciences (USA) 100:8916-8920.

Foster, B. L., V. H. Smith, L. Dickson, and T. Hilderbrand. 2002. Invasibility and compositional stability in a grassland community: relationships to diversity and extrinsic factors. Oikos 99:300-307.

Grime, J. P. 1973. Competitive exclusion in herbaceous vegetation. Nature 242:344-347.

Hobbs, R. J., and L. F. Huenneke. 1992. Disturbance, diversity, and invasion: implications for conservation. Conservation Biology 6:324-337.

Hooper, D. U., et al. 2005. Effects of biodiversity on ecosystem functioning: a consensus of current knowledge. Ecological Monographs 75:3-35.

Houghton, J. T., Y. Ding, D. J. Griggs, M. Noguer, P. J. van der Linden, X. Dai, K. Maskell, and C. A. Johnson, editors.
2001. Climate change 2001: the scientific basis. Cambridge University Press, Cambridge, UK.

Huston, M. A. 1979. A general hypothesis of species diversity. American Naturalist 113:81-101.

Kennedy, T. A., S. Naeem, K. M. Howe, J. M. H. Knops, D. Tilman, and P. Reich. 2002. Biodiversity as a barrier to ecological invasion. Nature 417:636-638.

Knops, J. M. H., D. Tilman, N. M. Haddad, S. Naeem, C. E. Mitchell, J. Haarstad, M. E. Ritchie, K. M. Howe, P. B. Reich, E. Siemann, and J. Groth. 1999. Effects of plant species richness on invasion dynamics, disease outbreaks, insect abundances and diversity. Ecology Letters 2:286-293.

Lavorel, S., A.-H. Prieur-Richard, and K. Grigulis. 1999. Invasibility and diversity of plant communities: from patterns to process. Diversity Distributions 5:41-49.

Levine, J. M. 2000. Species diversity and biological invasions: relating local processes to community patterns. Science 288 : 852-854.

Levine, J. M., P. B. Adler, and S. G. Yelenik. 2004. A metaanalysis of biotic resistance to exotic plant invasions. Ecology Letters 7:975-989.

Levine, J. M., and C. M. D'Antonio. 1999. Elton revisited: a review of evidence linking diversity and invasibility. Oikos 87:15-26.

Lyons, K. G., and M. W. Schwartz. 2001. Rare species loss alters ecosystem function-invasion resistance. Ecology Letters 4:354-365.

MacArthur, R. H. 1970. Species-packing and competitive equilibrium for many species. Theoretical Population Biology $1: 1-11$.

Milchunas, D. G., and W. K. Lauenroth. 1995. Inertia in plant community structure state changes after cessation of nutrient-enrichment stress. Ecological Applications 5:452458.

Naeem, S., J. M. H. Knops, D. Tilman, K. M. Howe, T. Kennedy, and S. Gale. 2000. Plant diversity increases resistance to invasion in the absence of covarying extrinsic factors. Oikos 91:97-108.

Ortega, Y. K., and D. E. Pearson. 2005. Weak vs. strong invaders of natural plant communities: assessing invasibility and impact. Ecological Applications 15:651-661.

Post, W. M., and S. I. Pimm. 1983. Community assembly and food web stability. Mathematical BioScience 64:169-192.

Prieur-Richard, A.-H., S. Lavorel, K. Grigulis, and A. Dos Santos. 2000. Plant community dynamics and invasion by exotics: invasion of Mediterranean old fields by Conzya bonariensis and Conzya canadensis. Ecology Letters 2:412422.

Renne, I. J., B. F. Tracy, and I. A. Colonna. 2006. Shifts in grassland invasibility: effects of soil resources, disturbance, composition and invader size. Ecology 87:2264-2277.

Sheley, R. L., S. Kedzie-Webb, and B. D. Maxwell. 1999. Integrated weed management on rangeland. Pages 57-68 in R. L. Sheley and J. K. Petroff, editors. Biology and management of noxious rangeland weeds. Oregon State University Press, Corvallis, Oregon, USA.

Sheley, R. L., and J. K. Petroff, editors. 1999. Biology and management of noxious rangeland weeds. Oregon State University Press, Corvallis, Oregon, USA.

Stachowicz, J. J., H. Fried, R. W. Osman, and R. B. Whitlatch. 2002. Biodiversity, invasion resistance, and marine ecosystem function: reconciling pattern and process. Ecology 83:25752590.

Stachowicz, J. J., R. B. Whitlatch, and R. W. Osman. 1999. Species diversity and invasion resistance in a marine ecosystem. Science 286:1577-1579.

Stohlgren, T. J., D. T. Barnett, and J. Kartesz. 2003. The rich get richer: patterns of plant invasions in the United States. Frontiers in Ecology and the Environment 1:11-14.

Stohlgren, T. J., D. Binkley, B. W. Chong, M. A. Kalkhan, L. D. Schell, K. A. Bull, Y. Otsuki, G. Newman, M. Bashkin, 
and Y. Son. 1999. Exotic plant species invade hot spots of native plant diversity. Ecological Monographs 69:25-46.

Stohlgren, T. J., C. S. Jarnevich, G. Chong, and P. Evangelista. 2006. Scale and plant invasions: a theory of biotic acceptance. Preslia 78:405-426.

Symstad, A. J. 2000. A test of the effects of functional group richness and composition on grassland invasibility. Ecology 81:99-109.

Thomsen, M. A., C. M. D'Antonio, K. B. Suttle, and W. P. Sousa. 2006. Ecological resistance, seed density and their interactions determine patterns of invasion in a California coastal grassland. Ecology Letters 9:160-170.

Tilman, D. 2004. A stochastic theory of resource competition, community assembly and invasions. Proceedings of the National Academy of Sciences (USA) 1010:10854-10861.

Van Ruijven, J., G. B. De Deyn, and F. Berendse. 2003. Diversity reduces invasibility in experimental plant communities: the role of plant species. Ecology Letters 6:910-918.

Vilà, M., J. D. Corbin, J. S. Dukes, J. Pino, and S. D. Smith. 2006. Linking plant invasions to environmental change. Pages 115-124 in J. Canadell, D. Pataki, and L. Pitelka, editors. Terrestrial ecosystems in a changing world. Springer, Berlin, Germany.
Vitousek, P. M., J. D. Aber, R. W. Howarth, G. E. Likens, P. A. Matson, D. W. Schindler, W. H. Schlesinger, and D. Tilman. 1997. Human alteration of the global nitrogen cycle: sources and consequences. Ecological Applications 7:737750 .

Von Holle, B., and D. Simberloff. 2005. Ecological resistance to biological invasion overwhelmed by propagule pressure. Ecology 86:3212-3218.

Walther, G.-R., E. Post, P. Convey, A. Menzel, C. Parmesan, T. J. C. Beebee, J.-M. Fromentin, O. Hoegh-Guldberg, and F. Bairlein. 2002. Ecological responses to recent climate change. Nature 416:389-395.

Wardle, D. A. 2001. Experimental demonstration that plant diversity reduces invasibility -Evidence of a biological mechanism or a consequence of sampling effect? Oikos 95: 161-170.

Wedin, D. A., and D. Tilman. 1996. Influence of nitrogen loading and species composition on the carbon balance of grasslands. Science 274:1720-1723.

Zavaleta, E. S., and K. B. Hulvey. 2004. Realistic species losses disproportionately reduce grassland resistance to invaders. Science 306:1175-1177.

\section{APPENDIX}

Comparison of $R^{2}$ values in models where realized species richness (RSR) or realized functional richness (RFR) were used as covariates, block and water treatment were used as fixed factors, and various items were used as response variables (Ecological Archives E088-159-A1). 